\title{
MYTH BUSTED? CHALLENGING WHAT WE THINK WE KNOW ABOUT CHARISMATIC SPEECH
}

\author{
JAN MICHALSKY and OLIVER NIEBUHR
}

\begin{abstract}
Charisma is a complex phenomenon. This fact manifests itself not least in an abundance of myths, half-truths, and unanswered research questions. Most charisma myths have not been uncontroversial, and since empirical investigations have advanced quickly over the past years, we take the opportunity in this paper to revisit ten of the most important myths that relate primarily, but not exclusively, to the linguistic and phonetic aspects of charisma, such as the interactions between verbal and nonverbal and between segmental and prosodic cues, as well as the roles of breathing and fundamental frequency in charisma perception. The result is a very diverse picture. Some myths, including very old ones, can be accepted. Others must be rejected in the light of contradicting empirical results. The status of some myths remains unsettled. Furthermore, in discussing that diverse picture, our paper points towards knowledge gaps in research and practice and gives concrete directions as to where to go from here.
\end{abstract}

Key words: Charisma, speech prosody, rhetoric, public speaking, posture, breathing, personality traits

\section{Introduction}

Research conducted in the field of charismatic leadership and speech is exemplary for the discrepancy between what we believe we know and what is actually empirically grounded. Furthermore, what we think we know has become so prevalent over time that it resulted in well-known, often undisputed myths. In this paper we address ten of the most frequent charisma myths along with the questions: What makes charisma so susceptible to myth-building? Is there empirical evidence to support prevailing statements about charisma? And if not, what may have caused these misconceptions? First of all, we find that charisma itself has been a myth from the start and to a certain degree remains a myth even today. The idea of charisma as an instrument of persuasion dates back to classical Aristotelian rhetoric (Antonakis et al., 2016). Early research viewed charisma as a mystical and even magical or alchemistical gift endowed at birth to a selected few (Weber 1947; Gemmill \& Oakley 1991: 119; see Antonakis et al., 2016 for an overview). Thus, charisma, by definition, exceeded the grasp of scientific understanding in that it was not a concrete skill but a variety of different subjective traits that, together, create 
a charismatic impression. Charisma was described as a social illusion (Gemmill \& Oakley 1991: 119) that magically empowered - often divinely chosen - leaders to pave the way out of a crisis (Weber, 1947). Accordingly, research on the mechanisms of charisma is relatively scarce. How can one study something that is magic and impossible to get hold of?

The scarcity of earlier empirical investigations on charisma contrasts with the need for a consistent concept of charisma and the understanding of its mechanisms when it comes to its use in economics and leadership training. It is commonly believed that charismatic leaders possess extraordinary abilities to motivate followers and to assert influence (Weber, 1947; Etzioni, 1964; House, 1977; Bass, 1985; Antonakis et al., 2016), which sparked a great deal of interest in teaching charisma and in using it as a tool for political-career and business development. This can be deduced from the vast body of popular advice literature on the topic (e.g., Mortensen, 2011; Soorjoo, 2012; Fox Cabane, 2012; Volkmann, 2013; Peters, 2015; Amon, 2016, inter alia). However, the lack of empirical research limits the applicability of the concept of charisma to everyday situations. In particular, coaches and consultants, as well as politicians and managers attempted to understand the sources of perceived speaker charisma and developed techniques to teach these sources (e.g., Fox Cabane, 2012). Over the course of time, this desire to understand that "ineffable quality that attracts, fascinates, and influences people around you" (Peters, 2015:1) without an established research paradigm or empirical background has led to a large number of assumptions based on impressionistic, anecdotal, and subjective observations, or on research that does not meet modern scientific standards. Furthermore, since those assumptions remained unchallenged by the scientific community and were continuously shared in an expanding scene of business coaching and consulting without ever having been testable hypotheses, they were declared common knowledge and became myths.

The research on charisma has expanded considerably over the past 10 to 15 years. While the earlier studies in political science, social science, and psychology laid the ground work to unravel the nature of charisma (Weber, 1947; Davies, 1954; Etzioni, 1964; Tucker, 1968; House, 1977; Bass, 1985), recent advances in leadership studies arrived at an operationalizable definition of charisma (Antonakis et al., 2016). Furthermore, charisma has been conceptualized in a set of modern as well as classical rhetorical devices that could be and have partly already been empirically tested (cf. Shamir et al., 1994; Emrich et al., 2001; Antonakis et al., 2011, 2015, 2016). In spite of this vast progress in delivering empirically grounded results and insights into charismatic leadership and speech, many researchers as well as practitioners (i.e. leaders and speakers) still rely on the established myths; the transfer from empirical research to everyday application and education is slow.

Interdisciplinary research on various facets of charisma has reached a point where it is deemed fruitful to revisit and reevaluate some of the most common myths in order to assess the actual status quo of what is known about charisma. This is precisely the objective of this paper. Moreover, and more importantly in fact, we want to challenge what is commonly declared to be known, namely 10 of the most frequent myths of charismatic leadership, particularly with respect to charismatic speech and delivery. The latter specification already implies that the 10 myths addressed here not do represent the top 10. It would probably be difficult to define on objective grounds and/or with reference to some 
external criteria what the top-10 myths about charisma actually are. Should we look at their persistence, i.e. for how long they have already been around, or at their frequency of occurrence in literature or the internet, or should we perhaps even rely on an estimate of how harmful or beneficial they are from a socio-economic perspective? As all of this seems inappropriate, the 10 myths we address here have been selected on a subjective basis insofar as they reflect the authors' own research activities and the field of research of the special issue in which this paper is published, i.e. phonetics or, more generally, communication signals. Therefore, we by no means claim that the selected 10 myths are the most important ones, nor does our selection imply that other myths are not worth being addressed and revisited.

In the following, we investigate which statements about charisma have passed the test of time and still hold to scientific standards, which statements have to be adjusted to fit empirical data, and which statements have to be rejected entirely, either due to a shift in the concept of charisma and how it is conveyed, or for being a general misconception. Furthermore, we do not just want to confirm or reject common myths based on empirical evidence. We also seek to explain why a myth may be considered true, based on the mechanisms of charisma, as well as why some myths have emerged at all.

\section{Myth 1: Charisma makes a difference}

The interest in making charisma a learnable skill comes from the assumption that charismatic leaders possess extraordinary powers to influence people in ways uncharismatic leaders cannot (cf. Weber, 1947; House, 1977; Bass, 1985; Antonakis et al., 2016). Furthermore, these charismatic ways of influence are said to not only differ from, but also have at least equal effects as authoritative leaders can assert through the power given by their position in the social hierarchy, as well as the effects that transactional leaders can achieve through the use of incentives (Howell \& Frost, 1989; Judge \& Piccolo, 2004). There is common ground in the advice literature that charisma makes a difference and that leaders should strive to become more charismatic. As is stated provocatively by Peters (2015: 29): "Charisma works like magic, it can put you in front of other people even though you know less than others (most of the country leaders will agree on this)".

That charisma makes a difference is indeed supported by empirical evidence. One of the first empirical studies by Howell and Frost (1989) shows that a charismatic leadership style increases the quality of output and efficiency of participants. Furthermore, Howell and Frost (1989) compared leadership styles and found that the effects of charismatic leaders outperformed those of compassionate and even structuring and hence more authoritative leaders. Further evidence is provided by Towler (2003). She found that HR personnel instructed by leaders who received charisma training performed with higher precision and produced greater task quality. A recent study by Antonakis et al. (2015) also supports the extraordinary effectiveness of charismatic leaders by showing that followers instructed by charismatic leaders work much more efficiently while retaining a high level of quality. Furthermore, Antonakis et al. (2015) compared the charisma effect to the influence of financial incentives and found that they increased productivity to the same degree, making a charismatic leadership style as effective as a transactional style without the additional costs; or in the words of Antonakis published in an online transcript 
by Pangambam (2016): "This charisma result is crazy because it's not well explained by current economic theory. We got increased performance, basically for free. And charisma significantly decreased production costs. We got increased performance without paying economic incentives." Additionally, studies show that vocal features of charisma alone exhibit a significant charisma effect by encouraging listeners to do more voluntary work, influencing their choice when booking a sightseeing trip or choosing healthy fruits over unhealthy sweets (Fischer, 2018), as well as affecting how willing they are to follow directions to a destination given by a car navigation system (Niebuhr \& Michalsky, 2019).

Not only do we have increasing empirical evidence that charisma does works but also why and how. In contrast to earlier descriptions, we can assume that the power of charisma is neither divine nor magical nor entirely subjective and indescribable. As Antonakis et al. (2016) define it, charisma is a device for emotion-laden, values-based, symbolic leadership signaling. Accordingly, charisma conveys that leaders are competent and confident in their abilities, convinced of the vision they entail, emotionally invested in, and passionate about their goals and agenda and, finally, also able to signal these properties through ways of communicating. Followers are inspired by passion, convinced of their common goal and vision through confidence in their leader, and consequently develop an intrinsic motivation to work for their common goal rather than merely because they have to obey orders. This is also supported by empirical evidence. In the study by Howell and Frost (1989), the participants in the charisma group reported higher satisfaction with both the task and the experimental environment in general. They were also much less or not at all affected by the expressed motivation of their peers in the groups, which is an indicator of robust intrinsic motivation. The charisma group in Towler's (2003) study also reported higher overall satisfaction. Furthermore, they reported perceiving the charismatic instructor as more efficient, competent, and convincing. Ning (2019) shows that participants in a brainstorming workshop rate themselves as more intelligent, unconventional, and capable, when the workshop is given by a more charismatic moderator. Lastly, the study by Niebuhr and Michalsky (2019) shows that listeners even project the charismatic features of trustworthiness and competence to a computer system when receiving instructions with a charismatic tone of voice.

Bottom line: The myth that charisma makes a difference is valid. The assumption that charismatic leaders inspire followers to achieve more and higher quality work is supported by a number of empirical studies. Their results even suggest that charismatic leaders not only surpass uncharismatic ones, but also that the effect of charismatic leadership outperforms the classical structuring leadership style that relies on authority from the social hierarchy, and that the effect of charismatic leadership achieves the same results as financial incentives given in a transactional leadership style. Furthermore, studies suggest that leaders who communicate in a charismatic way are perceived differently by their followers in terms of motivation, passion, confidence, and competence, which significantly affects self-reported satisfaction, motivation, confidence, intelligence, and capability. 


\section{Myth 2: Charisma is a divine talent of a few gifted people that only surfaces during a crisis}

Max Weber describes charisma based on the collective prior observations and concepts as "an extraordinary power, giving leaders salvationist qualities to deliver followers from great upheaval" (Weber, 1947, 1968). Accordingly, in this and earlier accounts, charisma was not only assumed to be a magical and indescribable feat, it was also considered an innate talent that only a few gifted people were able to develop during times of great need. Moreover, even those chosen few could not deliberately improve or change their charisma through training. It emerges and is shaped as a reaction to difficult times, specifically a crisis, and is spawned and enhanced by the people's need for a charismatic leader. Accordingly, charismatic speech should not be learnable or improvable by anyone, not even by those who possess the innate gift.

This perspective has been challenged from its inception by several researchers from psychology through the social sciences to business and management research; see, for example, Etzioni (1961), House (1977), or Shamir and Howell (1999). In addition, the modern advice literature arrives at the claim that charisma can in fact be learned by anyone:

"There's an often repeated myth that you're either born a great pitcher or you're not. ${ }^{1}$ This myth simply provides a justification for not preparing properly and an excuse for why pitches fail. The truth is that these so-called naturals put in days, and sometimes weeks, of preparation and use an array of proven strategies and techniques to consistently win over their audiences" (Soorjoo, 2012:xv).

Furthermore, it is suggested that charisma has to be trained even by the most proficient natural talents:

"We understand that proficiency at chess, singing, or hitting a fastball requires conscious practice. Charisma is a skill that can also be developed through conscious practice [...]. I know that a person's charisma level can be changed because I've helped countless clients increase theirs in this way" (Fox Cabane, 2012: 7).

What was assumed by earlier studies and additionally derived from anecdotal evidence in the advice literature has since been supported by empirical studies. The study by Howell and Frost (1989) investigated the results of charismatic, compassionate, and structuring leadership by training actors such that they were able to consistently apply the respective leadership styles. The results suggest that a charismatic leadership style can be convincingly learned and displayed by trained actors. Frese et al. (2003) extended the study of learnability of charisma to top managers and business leaders in a controlled design. They found that the charisma group improved in all relevant parameters of charisma such as communicating a vision, developing a collective identity, and having a stronger, more confident and more dynamic and expressive appearance as well as a so-called "captivating" tone of voice. Towler (2003) pushed this line of research further by teaching business students and achieved the same effects, i.e. an increase in symbolic

1 A "pitch" is a specific form of public speech given in business contexts. It "is usually less than two minutes in length, provides an initial glimpse of [a] venture idea with the goal of engaging the investor in further conversation and, ultimately, obtaining financing" (Clingingsmith \& Shane, 2017: 5164). In a more general sense, a pitch is any kind of public oral presentation that aims at persuading listeners. 
communication and a captivating tone of voice through charisma training. The study by Antonakis et al. (2011) was again aimed at managers and business leaders. However, they tried to teach charisma through a very specific set of Charismatic Leadership Tactics (CLTs) to make charisma training more efficient and tangible. Their study shows that all CLTs could be successfully learned by naïve speakers, and that they significantly increased the participants' perceived leader prototypicality.

The second author of this paper runs a 12-week course on Persuasive Communication and Negotiation that is mandatory for all master's students in electrical and business engineering at the University of Southern Denmark. It starts with the verbal CLTs and, based on this foundation, puts the focus on nonverbal aspects of body language and, in particular, speech melody. At the end of the lecture term, the students' presentations are rated with respect to perceived speaker charisma by an expert panel of lecturers and company leaders as well as by a sample of naïve listeners in an online experiment (between 50-100 people each year). Both experts and naïve listeners receive paired stimuli representing each student's baseline performance at the beginning of the course and his/her trained performances at the end of the course. The order of the stimuli within a pair as well as of the pairs themselves is randomized, and pairs are presented several times. The listeners' task is to indicate in which of the two compared presentations the speaker is more charismatic and to rate the higher level of charisma on a scale from 1 to 10 . Results show for all classes taught so far that the students have an about 40-90\% higher perceived charisma level at the end than at the beginning of the course, in the ears of experts even more so than in the ears of naïve listeners. Research based on automated acoustic charisma quantification shows additionally that a 4-hour intensive training of a speaker's voice can significantly increase speaker charisma by $10-50 \%$ and that female speakers benefit from such training more than male speakers do (Niebuhr et al., 2019).

Bottom line: The myth is busted that charisma is an innate talent that only manifests in times of crisis. Several studies have shown that signaling charisma can be trained by naïve speakers ranging from professional actors, through managers and business leaders to business and engineering students. However, there seem to be restrictions as to the degree to which charisma can be learned. As Antonakis et al. (2016) point out, proficiency in charismatic communication may be related to intelligence and/or creativity, as some CLTs such as metaphors and storytelling require a higher degree of creativity, innovation, and planning. Furthermore, as we discuss in the next chapter, the ability to convey charisma may be affected by personality or, as we see in Myth 10, general social skills or professional mindsets.

\section{Myth 3: Charismatic communication is the expression of a charismatic personality}

There is one common thread that connects all previous investigations of charisma. Weber (1947) described charisma as an extraordinary property of charismatic leaders. Charismatic leaders are said to be able to connect with their followers (Davies, 1954) and to possess a vision as well as confidence in their ideals and competence (Tucker, 1968). Furthermore, charismatic leaders are idols and exemplary personalities who care about their image (House, 1977). What all these assumptions have in common is that charisma 
is something that charismatic leaders have and which constitutes a part of their personality. That is, charisma is considered a personality trait. This basic notion was already largely rejected in the discussion of the last myth. As we have seen, charisma can be learned and improved. As described above, Antonakis et al. $(2011,2016)$ reject charisma as a property of charismatic leaders. Rather, charismatic leaders are not charismatic per se but possess the ability to communicate in a charismatic way. Consequently, in the studies by Howell and Frost (1989), Frese et al. (2003), and Towler (2003), the participants did not learn to become more charismatic people. They acquired communicative skills to convey charisma.

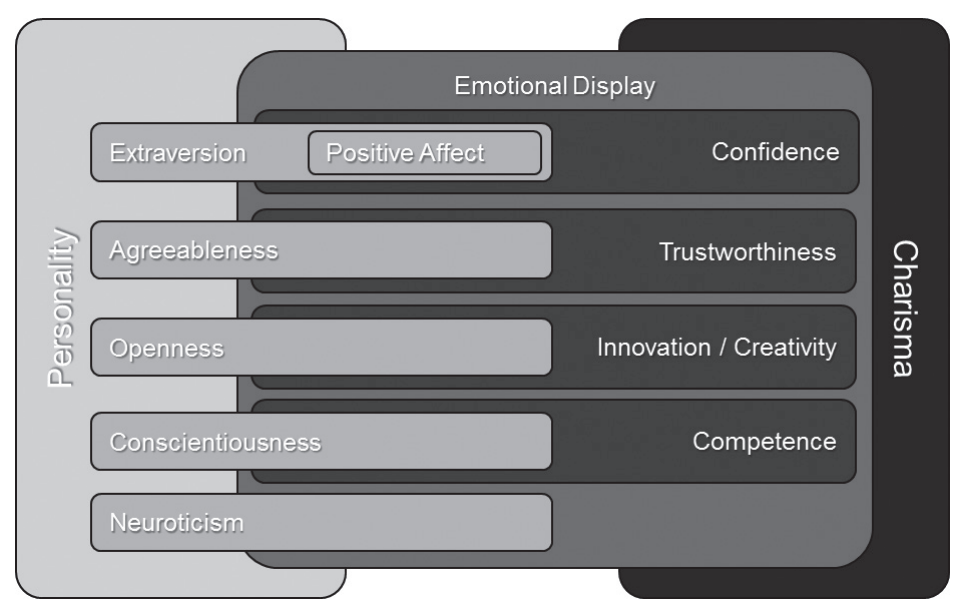

Figure 1. Intersections between personality types according to the Big Five Personalities paradigm (Costa \& McCrae 1992) and features of perceived charismatic personality (Antonakis et al. 2016).

However, even without perceiving charisma as a personality trait, there may still be traits that significantly influence a speaker's ability to acquire a charismatic way of communicating. That is, certain personality types foster ways of communicating that coincide with charismatic speech; see Figure 1 and Peters (2015). There are in fact two integral parts to charismatic speech according to Antonakis et al. (2016): confidence and self-assuredness, as well as passion and display of emotions. When it comes to the big five personality traits that are commonly used for assessing speaker personalities (Costa \& McCrae, 1992; Sharma et al., 2013), both confidence and displaying emotions relate to the personality trait of extraversion. When it comes to the phonetic properties of charismatic speech, we find similarities between the phonetic manifestations of extraversion and charismatic speech. Acoustic characteristics associated by listeners with extraversion, such as an expanded fundamental frequency $\left(f_{0}^{2}\right)$ range, an elevated $f_{0}$ mean, more frequent and deeper final falls, as well as a higher speaking rate, resemble the acoustic characteristics of charisma (Michalsky et al., 2019). Furthermore, extraversion is linked

2 Fundamental frequency, or $f_{0}$, is the acoustic correlate of the vocal-fold vibration frequency in speech production; $f_{0}$ is used by listeners as the main source of pitch perception. Thus, in a nutshell, $f_{0}$ movements in speech represent a speaker's speech melody. 
to positive affect, a trait which is also related to higher confidence, higher personal goals, as well as to experiencing and expressing positive emotions more frequently (Costa \& McCrae, 1992; Curhan \& Brown, 2012). The trait of agreeableness also relates to concepts relevant for expressing charisma. Agreeable speakers are assumed to be kinder and warmer, which relates to the ability of charismatic leaders to connect with people and, furthermore, to show a greater ability to express and develop trust (Costa \& McCraw, 1992; John \& Srivastava, 1999). Conscientiousness is related to self-discipline and overall job performance (Costa \& McCraw, 1992; John \& Srivastava, 1999; Barrick \& Mount, 1991). Lastly, openness can be regarded as a measure of imaginativeness and divergent thinking (Costa \& McCrae, 1992; John \& Srivastava, 1999). Since a significant portion of the CLTs that result in the necessary emotional symbolic communication is contributed by strategies such as metaphors and storytelling, creativity and imaginativeness constitute integral parts of charismatic communication (Antonakis et al., 2011).

Bottom line: The myth that charismatic speech and communication are mere expressions of a charismatic personality has been largely busted in its strict form. Charisma itself is a way of communicating that can be learned, improved, and implemented independently of personality traits. There are good reasons to assume that certain personality traits naturally lend themselves to support charismatic speech. However, we saw that there is no single charismatic personality type. Rather, it is a mixture of different personality types that supports speaker charisma. People may communicate in charismatic ways through different strategies by approaching charisma either through the self-assured and confident facet of being extraverted, through the passionate and emotional facet of being positively affective, through the expressive/symbolic facet of being high in openness, through the trustworthy facet of being agreeable, through the competent facet of being conscientious, or through a combination of any of these. It is unlikely that the majority of charismatic leaders possess a charismatic personality that includes all or only just the majority of these traits; and it is even more unlikely that this is required to learn a charismatic performance. That is, charisma itself is not necessarily a matter of personality.

\section{Myth 4: How we say something is more important than what we say}

Another frequently reappearing assumption about charisma is that the delivery of a message matters more to the listener than the message's content. However, we first have to establish where to draw the line between how and what, since this issue in itself is a controversial topic (see Figure 2). From a linguistic perspective, it is reasonable to distinguish between linguistic content and paralinguistic delivery. However, in classical rhetoric and, in fact, in the majority of psychology, social-science, and management/ leadership studies, content and delivery are already separated at a linguistic level. Following classical rhetorical research as well as Antonakis et al. (2016), only the speaker's propositions are regarded as content, whereas linguistic rhetorical devices like rhetorical questions, lists, contrasts as well as metaphors, analogies, and devices of storytelling are all part of the delivery. Although this distinction is most common and also adopted in this paper, there are other approaches arguing that rhetorical strategies belong to the 
content rather than the delivery (Shamir et al., 1994). Following Antonakis et al. (2016), the myth would claim that how we say something both in term of voice as well as rhetorical strategies and visual cues outweighs the propositions of a speech. This is supported by the aforementioned study by Antonakis et al. (2015) who tested the effect of the same propositions delivered using different linguistic, visual, and prosodic devices. Although the speakers' propositions were identical, the delivery strategy significantly affected perceived charisma.

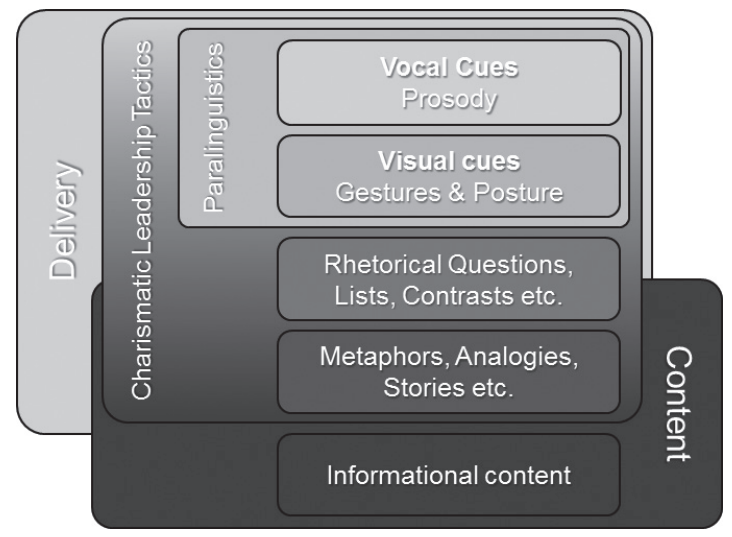

Figure 2. What we say and how we say it. Different classifications of content and delivery.

The other common distinction is the separation of linguistic content from paralinguistic delivery, with paralinguistics encompassing both vocal and visual features, but not linguistic rhetorical strategies. Accordingly, the myth would claim that how we say something in terms of acoustic-prosodic and visual (i.e. overall nonverbal) cues outweighs the propositional as well as the linguistic content. This distinction is frequently found in the advice literature. As Soorjoo (2012: 20) points out: "Yet, when it comes to preparing a pitch, most people tend to focus on the content of their speech and their PowerPoint... This is one of the principal reasons why most people deliver bad pitches". Fox Cabane (2012) also claims that "nonverbal modes of communication are hardwired in our brains, much deeper than the more recent language-processing [i.e. word-related] abilities, and they affect us more strongly" (p. 89). This common assumption manifests itself also in proverbs like "hitting the right note".

The dominant role of vocal features in the field of charismatic persuasion becomes apparent in several empirical studies. Holladay and Coombs (1993) found that if there is an apparent contradiction between a speaker's verbal and non-verbal message, the latter is more likely to influence a listener's perception (see also Holladay \& Coombs, 1994). Towler (2003) conducted a principal component analysis to separate different contributors to charisma and found that vocal features provided an independent and crucial effect. Pentland (2008) investigated the impact of paralinguistic cues including both gestures and acoustic-prosodic features in several social settings and found paralinguistic cues to successfully predict the success of investor pitches, the exchange of business cards after a meeting, the success in acquiring new customers, and even the exchange of phone 
numbers after speed dating. Several comparable findings on the dominance of delivery over content have been made (Awamleh \& Gardner, 1999; Gregory and Gallagher, 2002; Park et al., 2014). Just recently, Caspi et al. (2019) conducted two experiments on the topic and found that delivery significantly outweighs the content when it comes to a first impression of a speaker, which is supported by the findings of McAleer et al. (2014), who found that the delivery of a simple "hello" already critically affects the impression we make about a speaker personality. Sometimes even the visual cues such as gestures and posture are excluded from the how and the major role is solely attributed to the acoustic-prosodic features of charisma. Amon (2016) claims that "there is a superiority of the audible impression over the visible. The moment you open your mouth, all the visible elements become mere decoration" (Amon 2016: 12, the authors' translation). In their multimodal analysis of speaker charisma, Scherer et al. (2012) found that auditory cues alone affect perceived charisma and enhance and even shift the interpretation of visual cues. Chen et al. (2014), who conducted a similar analysis, arrived at the conclusion that auditory cues outweigh visual cues as a predictor for charisma. Lastly, the studies done by Fischer (2018) as well as Niebuhr and Michalsky (2019) show that computer voices possess charismatic influence even if the lexical material is identical, visual cues are absent, and only acoustic cues serve to signal charisma.

Bottom line: Regardless of whether we include rhetorical strategies in the delivery side of speech, restrict ourselves to paralinguistic cues, or to acoustic-prosodic features alone, empirical research supports that how we deliver a speech significantly contributes to its charismatic and persuasive impact. Furthermore, we can assume that the delivery is more important in signaling charisma. However, although the how is essential for a charismatic performance, to date there is not a single study that actually compares the charismatic effect of content against the charismatic effect of the delivery for neither definition of delivery. Following Emrich et al. (2001) it is possible that delivery is crucial for the immediate impact of a charismatic performance but the effects diminish in the long run, if not supported by the content (see also Caspi et al., 2019). Accordingly, although this chapter strongly suggests that the how outweighs the what, we can neither completely reject nor accept the myth in this simple form.

\section{Myth 5: Lower voices are more charismatic}

"How to Train Your Voice to Be More Charismatic?" In answering this question, Nancy Daniels (2013) points her readers to the study of Mayew et al. (2013). Based on voice-pitch analyses of 792 leaders (CEOs of major companies) around the globe, and controlling for other confounding factors, Mayew et al. conclude that low voices make better leaders. More specifically, speakers showing an interquartile decrease in $f_{0}$ level of $22.1 \mathrm{~Hz}$ enjoy longer tenures (about 151 days longer), lead larger and higher-valued companies (by about $\$ 440$ million) and, thus, earn more money (about $\$ 187,000$ more per year). Carnegie and Esenwein (2011: 32) also criticize in their rhetoric manual the fact that "most speakers pitch their voices too high" while presenting; and Barker (2011) paraphrases the same criticism in the form of an imperative: "Create vocal music that is lower in tone, slower and softer, and you will create rapport more easily" (p. 14), which 
is later in the book narrowed down to $f_{0}$ alone: "Lower your tone. A thin, high-pitched voice will suggest a lack of authority or confidence" (p. 175).

Together, these interdisciplinary findings, statements and instructions seem to form a coherent whole: The lower-pitched you speak the more charismatic you sound. In fact, exactly the opposite is true. When looking beyond management and psychology studies and rhetoric manuals and anecdotes, readers will quickly find consistent evidence from the experts in that matter, i.e. speech scientists, that the correlation between a speaker's $f_{0}$ level and his/her perceived speaker charisma is positive, not negative. This finding was made, for example, by Touati (1993), Strangert and Gustafson (2008), Biadsy et al. (2008), Rosenberg and Hirschberg (2009), D’Errico et al. (2013), Berger et al. (2017), Jokisch et al. (2018), and Niebuhr and Skarnitzl (2019) whose studies cover languages that range from English to German and Swedish to Italian, French, and Arabic.

In the light of such obvious and abundant counterevidence, why does the myth that lower voices are more charismatic still persist? There are several reasons. First, charisma is a fuzzy semantic concept, and studies advocating lower pitched voices often do not investigate charisma, at least not in its current prototypical sense. Recall that charisma is defined as the ability to gather and win over people and determine their opinions, attitudes, and actions, without exercising authority and control and without using formal mechanisms (cf. Antonakis et al., 2016). As Smith (2010) puts it, charisma "equals persuasion with force", with persuasion being based on emotional contagion. In contrast, studies advocating lower pitched voices often refer to terms like dominance, authority, and power. In short, it is the lack of a clear distinction between dominance and authority on the one hand and charisma on the other that creates the inconsistency in voice-pitch related recommendations to speakers. A low-pitched speaker conveys power and authority and, on this basis, tells people what to think and do. A high-pitched speaker conveys charisma and, on this basis, makes people adopt his or her point of view so that the intended thoughts and actions are elicited on a voluntary basis. ${ }^{3}$

Figure 3 shows the pitch levels of two undoubtedly charismatic speakers, Barack Obama and Steve Jobs, in relation to the frequency of occurrence of voice-pitch levels among the populations of male and female American English speakers. As can be seen, both Obama and Jobs speak at such high pitch levels $(217 \mathrm{~Hz}$ and $232 \mathrm{~Hz}$, respectively) that they already fall in a voice-pitch range that is characteristic of female speakers in American English (see Niebuhr et al., 2016; D'Errico et al., 2019 for the sources of the mean values of the two speakers). Although these female speakers were reading calibration sentences whereas Obama and Jobs were giving public speeches (with a louder and hence inherently higher-pitched voice), this is still a remarkable observation against the background of a myth claiming that it is a low-pitched voice that makes a charismatic speaker.

The second reason for the persistence of the myth that lower voices are more charismatic lies in the confusion of local and global pitch levels. While a speaker's global pitch

3 However, note that, although dominant and authoritative speakers have a lower voice than charismatic speakers, their average pitch level is not extremely low but still within the lower mid of their pitch range, probably because of a high loudness level and a way of speaking that is meant to convey urgency and righteous indignation. Humble speakers can still have a lower pitch level than dominant/ authoritative speakers, especially in dialogue situations (D’Errico et al., 2019). 
level should be overall higher to be more charismatic, charismatic speakers must also be able to get down to the bottom of their individual pitch ranges at certain local points in their sentences. This primarily applies to the pitch valleys in between to expressively stressed, high-pitched words and, in particular, to the ends of sentences. This is very well described by Fox Cabane (2012: 89): "imagine an assertion: a judge saying 'This case is closed. Feel how the intonation of the word 'closed' drops. Lowering the intonation of your voice at the end of a sentence broadcasts power. When you want to sound superconfident, you can even lower your intonation midsentence." In accord with this statement, Mixdorff et al. (2018) showed that charismatic speech means a raising of pitch peaks and the speaker's overall pitch level and, at the same time, a lowering of the "baseline $f_{0}$ ", i.e. those local levels at which a speaker begins his/her pitch rises towards stressed words and ends his/her sentence-final pitch falls.

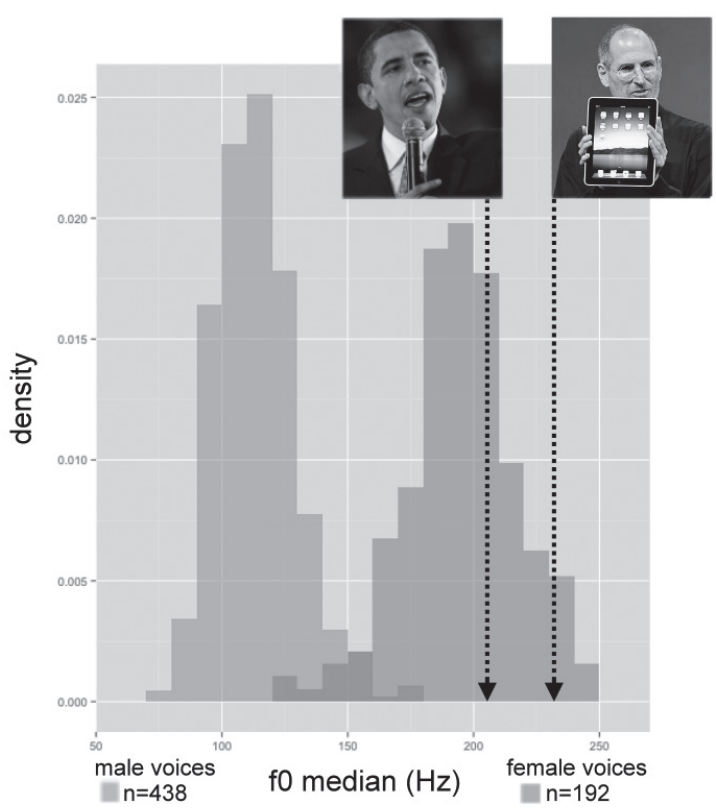

Figure 3. $f_{0}$ medians of Steve Jobs and Barack Obama during public speeches, compared to the $f_{0}$ medians of 630 male and female speakers of American English who read the two calibration sentences of the TIMIT database. The histogram was edited after Liberman (2013). The photographs were edited and added to the figure based on a Wikipedia creative commons license.

The third reason is related to the relevance of the pitch-level factor for a speaker's charismatic impact. Although the positive correlation between pitch level and speaker charisma is strong and significant across languages, the perceptual relevance of the factor pitch level is actually rather low. Several perception experiments arrived at the conclusion that other factors like speaking rate, pitch range, pause frequency and duration, as well as filled pause characteristics have a much stronger effect on listeners' speaker charisma ratings than a speaker's global voice-pitch level (Berger et al., 2017; Niebuhr et al., 2017). Thus, even if speakers follow the recommendation to lower their pitch level instead of 
raising it in order to sound more charismatic, this wrong decision has no strongly negative effect on their overall charismatic impact, as long as they perform well along other more important voice factors.

Bottom line: The myth that lower voices are more charismatic is busted by cross-linguistic empirical evidence from the speech sciences. Speakers should raise rather than lower their global pitch level. However, local pitch levels that are reached between expressively stressed, high-pitched words and at the ends of utterances should indeed be lowered to the bottom of a speaker's individual pitch range, i.e. where the voice starts getting creaky (i.e. irregular and crackling) in the case of male and breathy in the case of female speakers.

\section{Myth 6: A clear pronunciation supports perceived speaker charisma}

"Distinct and precise utterance is one of the most important considerations of public speech. How preposterous it is to hear a speaker making sounds of 'inarticulate earnestness' under the contended delusion that he is telling something to his audience! [...] Telling means communicating, and how can he actually communicate without making every word distinct?" (Carnegie and Esenwein, 2011: 146). Not every statement is as strong as the one above from The Art of Public Speaking, but virtually every rhetoric manual urges its readers to "clearly articulate every phrase and word" and to internalize that "good articulation conveys competence and credibility" (Mortensen, 2011: 158) and, thus, "is imperative to develop charisma” (Camper Bull, 2010: 138); see also Frese et al. (2003).

The contribution of articulatory precision to a speaker's charismatic impact is, unfortunately, not as well studied as the contribution of prosodic features like loudness, speaking rate, and pitch level or range, but the few studies that exist basically back up the rhetorical statements on articulation. For example, Niebuhr (2017) conducted a perception experiment whose stimuli included, amongst other things, a naturally produced systematic variation in the degree of speech reduction. Three controlled reduction steps were created: (i) sentences in which each word is pronounced in its full, dictionary-like fashion; (ii) sentences in which each word is pronounced like in an informal everyday conversation, i.e. slightly reduced in the case of content words and moderately reduced in the case of function words; (iii) sentences in which both content and function words are all equally pronounced as strongly reduced as possible. Results show that a constantly strong reduction makes speakers sound significantly more absent-minded, stressed, and clumsy and less trained/skilled, sociable, educated, optimistic, and sincere, i.e. overall less charismatic. This perception evidence is in accord with production evidence from a comparison of Steve Jobs and Mark Zuckerberg. Steve Jobs, who is perceived to be more charismatic than Mark Zuckerberg both by representatives of the media and listeners in a controlled perception experiment (Niebuhr et al., 2018a), performs significantly better than Zuckerberg in acoustically distinguishing his voiced and voiceless stop consonants (/p t k/ vs / b d g/) as well as the different vowel qualities of American English. The acoustic vowel space that Jobs uses in his speech is at least 32.7\% larger than that of Zuckerberg (Niebuhr and Gonzalez, 2019). Furthermore, Jobs' speech includes $28.3 \%$ fewer instances of post-lexical assimilation of alveolar consonants (/t $\mathrm{d} n /$ ) to either bilabial or velar plac- 
es of articulation than Zuckerberg's speech (Niebuhr et al., 2018a). This applies to content words; the relative difference between the two speakers is even larger for function words.

Finally, that articulatory precision contributes to a speaker's charismatic impact also makes sense in terms of the fundamental ethological principle of the Effort Code (Chen et al., 2002). In a nutshell, the Effort Code conceptualizes that the importance of a certain matter is positively correlated with the energy that is invested in addressing it (Gussenhoven, 2016). In speech, this means that whatever a speaker considers (more) important is realized with great(er) articulatory effort; and greater articulatory effort, in turn, "tends to create more elaborate and more explicit phonetic realisations" (Chen et al., 2002: 211), i.e. a clearer pronunciation. Thus, in terms of the Effort Code, the charisma effect of articulation is explained by a clearer pronunciation being an implicit signal of "I have something important and meaningful to say" and/or "you, my listeners, are important to me". Barker (2011: 176) explains speaking clearly to his readers as follows: "Make sure all the consonants are clear when you are speaking (all the letters that are not A, E, I, O or $U)^{\prime}$. Such a restriction of articulatory effort to consonants alone does not make sense in terms of the Effort Code; nor is there, to the best of our knowledge, any empirical evidence that persuasion relies more on consonant than on vowel articulation. Therefore, such recommendations should be treated with caution. The actual reason for Barker's focus on consonants is that they, unlike vowels, most often include a sensible contact between active and passive articulators, which makes self-monitoring and articulatory control easier for speakers (Abercrombie, 2000).

Bottom line: The myth that a clear pronunciation supports perceived speaker charisma is valid. It is consistent with empirical evidence as well as with theoretical concepts like the Effort Code. If one wants to qualify the myth, then by noting that realizing each and every word with a dictionary-like pronunciation can reverse the positive effect of a clear pronunciation and attenuate speaker charisma again. For example, Niebuhr (2017) found that such an "overarticulated" way of speaking makes a speaker sound more vain and less composed and sincere. However, without special training or instruction, native speakers are unlikely to attain this overarticulated level of pronunciation, as speech reduction probably belongs to the universal characteristics of spoken language (Clopper and Turnbull, 2018) and comes naturally to speakers through semantic or frequency effects or biomechanical and physiological limitations of the speech production apparatus (Cangemi et al., 2018). Therefore, it is reasonable to assume that the practical risk of strongly and constantly overarticulating one's presentation is low, except, maybe, for non-native speakers, but this is a question that needs to be addressed in future studies. Until then, all speakers should aim at a "crisp clear pronunciation" (Seet, 2013) when performing a speech. Whether this applies to the same degree for vowels and consonants is also a matter of future research.

\section{Myth 7: Filled pauses are bad for perceived speaker charisma}

It is a common statement in rhetoric manuals that speakers should, as much as they can, avoid all the errs, uhs, urns, ums, and $m h s$ in their speech that are referred to as filled pauses (or hesitation markers/disfluencies). For example, Sprague et al. (2013: 336) make 
the following recommendation in their Speaker's Handbook: "Do not be afraid to pause between sentences or thoughts when you speak. But avoid filling those pauses with distracting and meaningless sounds and phrases [...]". Similarly, Soorjoo (2012: 26) states that silent pauses are an effective way to "eliminate distracting nonwords such as ums and $u h$ s" from a speaker's speech. Learning to self-monitor one's speech and, on this basis, to anticipate and replace filled pauses by silent pauses is also a key point in the " 3 tips to eliminate filled pauses from your professional presentation" by Bell (2011).

At first glance, these strong statements and specific recommendations are backed up by empirical evidence from the speech sciences. For example, Biadsy et al. (2008) as well as Rosenberg and Hirschberg (2009) found, across languages, a negative correlation between filled pauses (and self-repairs) on the one hand, and charisma-related ratings of a speaker on the other. The works of Niebuhr et al. $(2016,2019)$ are consistent with these findings. Comparing the more charismatic Steve Jobs with the less charismatic Mark Zuckerberg revealed that the frequency of filled pauses (and other disfluencies) represents one of the biggest differences between the two speakers, with Jobs using $46.2 \%$ fewer filled pauses than Zuckerberg. Moreover, indirect perception evidence of Niebuhr and Fischer (2019) suggests that filled pauses are one of the major factors for the perceived charisma differences between the two speakers.

At second glance, however, the strong statements in rhetoric manuals need to be qualified in at least two respects. First, filled pauses per se are not bad - either for the comprehension and memory of a speaker's messages, or for his/her perceived charisma and related traits. Rather, the opposite is true. Filled pauses fulfill important communicative functions. They facilitate the listeners' cognitive processing of the upcoming information (in that they typically occur before less frequent words and/or new information); Corley and Hartsuiker (2003) call this the "um advantage". In addition, they indicate to listeners through their specific phonetic form how long they will have to wait until the speaker continues talking (Fox Tree, 2001) and whether the speaker continues with the same or a different message (Fischer, 2000). Furthermore, Fischer (2000) and Fruehwald (2016) stress that filled pauses serve important social functions in speech, such as mitigating potentially impolite utterances (Levinson, 1983; Schegloff, 2010) and showcasing a speaker's affiliation to a specific cultural or social group.

The second, more important reason why filled pauses should not simply be eliminated from a speaker's speech is that they convey spontaneity and listener-orientation. That is, they are critical "contact signals" (cf. Fischer, 2006). In accordance with that, Novák-Tót (2016) found that the former CEO of Hewlett-Packard, Meg Whitman, sounded less charismatic in the ears of listeners than the CEO of IBM, Virginia Rometty. This difference was, amongst others, traced back to the frequency of filled pauses, but not in the sense that Whitman used significantly more filled pauses than Rometty. Rather, Whitman used almost no filled pauses at all within almost 20 minutes of analyzed speech, as compared to 13 filled pauses in the case of Virginia Rometty (and 35 in the case of Steve Jobs; see Novák-Tót et al., 2017). More in-depth analyses in separate perception experiments show that the complete absence of filled pauses makes a speaker appear self-referred, arrogant, distant, and sounding as if s/he were reading a text rather than presenting a message.

Thus, recommendations of manuals that speakers must try to eliminate filled pauses altogether from one's speech are wrong and should not be followed. Obviously, it is the 
dose that makes the poison; and indeed some rhetoric manuals do point readers to that fact, but only in unspecific ways that are of limited help for speakers. For instance, Bell (2011) briefly notes that "using a filled pause one in 100 words is not problematic, using filled pauses one in five words is a big problem." (p. 12). Bell is one of few who provide the reader with specific numbers. Yet, the numerical range is huge and hence of limited practical help, and the statement is still oversimplified. Niebuhr and Fischer (2019) show in a charisma-related study on filled pauses that it is not the mere total number or relative frequency of filled pauses that matters for a speaker's impact on listeners, but the duration of filled pauses and the degree to which they are realized as a nasal element (e.g., $\mathrm{mmm}$ ). The shorter and more nasal filled pauses are, the more do listeners underestimate their actual physical number and frequency in a speaker's speech and the higher they rate the speaker's presentation performance. In other words, rather than trying to get rid of filled pauses (at the additional risk of losing listener-orientation and spontaneity), speakers should rather learn to produce short and nasalized filled pauses. That is, long errs and uhs should be replaced by shorter ums and $m h s$. More specifically, filled pauses with duration up to one syllable (300-400 ms) have only a marginally negative impact on a speaker's perceived performance, and filled pauses that consist more of a nasal than of a vowel sound can even add to a speaker's perceived performance (Niebuhr \& Fischer, 2019). To what extent this is language-dependent still needs to be determined. For now, it seems to hold at least for Western Germanic languages.

Bottom line: The myth that filled pauses are bad for perceived speaker charisma is busted, at least in this general form. Filled pauses perform important communicative functions, and trying to reduce one's filled pauses is only useful if their number is exceptionally high ( $>8$ items per minute). Working on the quality of filled pauses is more effective in terms of improving speaker charisma.

\section{Myth 8: Belly breathing and an upright posture support speaker charisma}

There is hardly any rhetoric manual without a chapter of 10 pages or more that is specifically dedicated to breathing. In books like Kraus (2015) and Volkmann (2013), the breathing chapter represents $8-17 \%$ of the entire text. In these chapters, authors often stress the relevance of the so-called "belly breathing" that relies on the speaker's diaphragm rather than on his/her inter-costal muscles whose activity is associated with "chest breathing". For example, Fox Cabane (2012: 192) reminds her readers: "make sure you're breathing deeply into your belly". Similarly, Carnegie and Esenwein (2011: 223) claim that "deep breathing - breathing from the diaphragm - give[s] the voice a better support [and] a stronger resonance" both of which are assumed key features of the art of (persuasive) public speaking. Likewise, it is concluded in Speech-and-Voice (2019) that "For optimal voice usage and projection, proper breathing must come from the midsection or diaphragm" (see also Goman, 2008 and Volkman, 2013). Barker (2011) draws a direct connection between belly breathing and persuasive (charismatic) speech by stating that "the deepest kind of breathing, which works from the stomach rather than the upper part of the lungs [...] works wonders for the voice: it gives it depth and power, and makes for a more convincing delivery" (pp. 132-133). 
Furthermore, the beneficial effect of belly breathing on public-speaking performance is often linked to an upright posture. Figure 4 shows three examples of breathing exercises from online and offline public-speaking manuals. They all recommend belly breathing, and, while instructions for experiencing and training belly breathing occasionally also include sitting and lying postures, the ultimate application of belly breathing during public speaking, as well as the related warm-up, is always closely tied to a standing posture. Standing upright, so rhetoric manuals claim, supports belly breathing in a charismatic speaking scenario and, moreover, "communicates a message of confidence" (Hargrave, 1995: 52) and similar desirable traits of a charismatic speaker (which is why an upright posture is also addressed additionally in the chapter(s) on body language in rhetoric manuals). As Fox Cabane says: "Be the big gorilla" (p. 251).

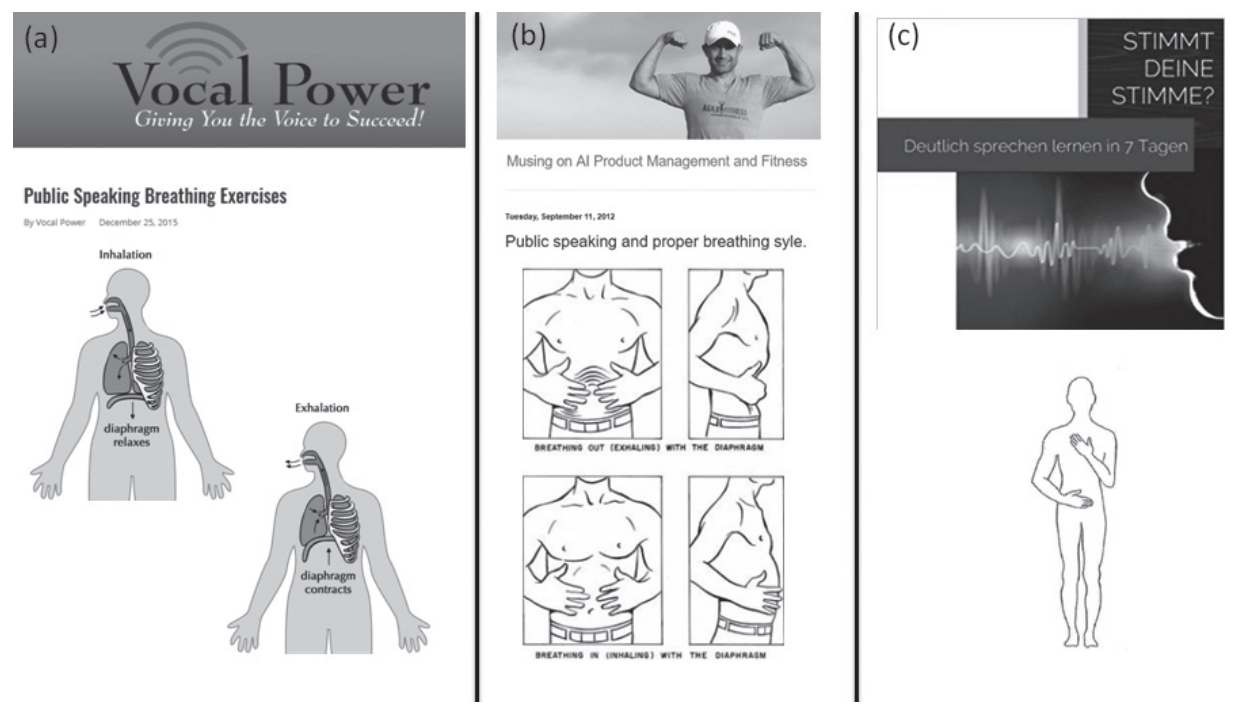

Figure 4. Three examples of belly-breathing instructions in the advice literature illustrated by means of a standing posture; (a) http://engage.vocalpower.ca/engage/public-speaking-breathing-exercises-2340, (b) http://www.manjeetjakhar.com/ 2012/09/public-speaking-and-proper-breathing.html, (c) Nico Kraus (2015); links were last accessed on June 3rd, 2019.

Barbosa and Niebuhr (forthcoming) recorded time-aligned speech and breathing signals (both belly and chest) of 18 native speakers of German, 9 men and 9 women, all of them early-stage entrepreneurs with experience in public speaking. The speakers were recorded while giving an investor pitch in front of an audience of peers, once while sitting and once while standing (the order was balanced across speakers). A sample of 21 German listeners rated the speakers' performances in terms of two criteria: (1) how charismatic (persuasive/confident/inspiring/passionate) does the speaker sound? (2) how resonant (relaxed/rich/sonorant/full) is the speaker's voice? Ratings were made on a scale from 1-6 (German school grading system). Additionally, acoustic-prosodic measurements positively correlated with speaker charisma were taken, including the levels, variation, or ranges of $f_{0}$ and intensity. 
Results show that the acoustic-prosodic measures do not benefit from belly breathing and an upright posture and that speakers do not sound more charismatic when they mainly rely on belly breathing and present in a standing rather than sitting posture. Rather, the opposite was found. That is, speakers who mainly used chest breathing while presenting were those whose acoustic-prosodic measurements and perceived-charisma ratings went up. Belly breathing had an effect as well, but only in terms of the perceived resonance of a speaker's voice. The more a speaker relied on belly breathing while presenting, the more resonant was his/her voice perceived by listeners. Barbosa and Niebuhr have, in the meantime, more than doubled the speaker sample and extended it to Danish and Russian speakers. The overall results pattern remains the same according to pilot tests.

Bottom line: The myth that belly breathing and an upright posture support speaker charisma is busted. It is true that belly breathing has a favorable effect on voice quality, which is also consistent with studies on singing and speech pathology (Salomoni \& van den Hoorn, 2016; Thorpe et al., 2001; Xu et al., 1991). However, this favorable effect does not include those acoustic-prosodic parameters that listeners use when rating speaker charisma. Given that, what the experiments of Barbosa and Niebuhr have falsified (based on the currently analyzed data) is the following implicit conclusion of rhetoric: Belly breathing is good for the voice and, therefore, it must also be good for charismatic speech. In fact, it is chest breathing that is good for charismatic speech; and this finding makes sense if it is looked at from the following angle: The positive effect of belly breathing in singing and speech pathology is associated with maintaining a powerful (i.e. loud), long exhalation phase. However, when it comes to speaking skills, it is the shorter rather than the longer prosodic phrase that makes speakers sound more charismatic (Biasdy et al., 2008; Rosenberg and Hirschberg, 2009). Thus, if charismatic speakers have to split up their messages into small acoustic sound bites of 2-3 s, why should they then benefit from belly breathing? Such short, impulse-like speech bites, often combined with very short, intensive inhalation phases, are better supported by chest breathing, for example, due to the intercostal muscles having a larger number of fast muscle fibers (Polla et al., 2004). Thus, the presented empirical evidence suggests to not invest too much time in learning to use and control belly breathing for public speaking. It gives speakers no measurable or perceivable advantage. The same applies to an upright posture. It is safe to give a charismatic presentation while sitting, at least in terms of speech acoustics and perception.

\section{Myth 9: A charismatic performance requires intensive training on part of the speaker}

The Speaker's Handbook (Sprague et al., 2013: 327) uses a salient red text box to warn its readers that "adequate practice is paramount to successful speaking". "Sitting and thinking about your speech, or reading over your outline or notes, is no substitute for rehearsing the speech aloud." (Sprague et al., 2013: 326). Barker (2011: 128), in his instructions to Improve Your Communication Skills, makes a similar point by raising readers' awareness for the fact that "there is a world of difference between thinking your presentation through and doing it. You may think you know what you want to say, but until you say it you don't really know. Only by uttering it aloud can you test whether you understand what you are saying. Rehearsal is the reality check" (Barker, 2011: 128). 
That a charismatic presentation performance requires intensive oral training is not a simple myth. It seems to be an axiom. In addition, most empirical research asks not if but rather focuses on how, which, and when speaker feedback should be given in the context of presentation rehearsal (e.g., Batrinca et al., 2013). What is neglected are the questions of how much oral rehearsal is actually needed and if it is needed at all under certain conditions, depending on the occasion, the speaker's educational background, his or her personality traits, and previous experience with public speaking. Soorjoo (2012: 76) states: "The more you rehearse, the better you will perform". It is not that straightforward, unfortunately. For example, some experienced charismatic speakers insist that intensively practicing an oral presentation is harmful for them as it reduces their spontaneity, flexibility, naturalness and, ultimately, also their fluency, because their minds are constantly distracted by trying to remember how the current argument was paraphrased most successfully during previous rounds of rehearsal. So, either such speakers do not practice enough to overcome these problems, or their experience of public speaking and the delivery patterns that they have internalized and automated while learning to become a charismatic speaker allow them now to largely skip an intensive oral rehearsal of individual presentations.

Such reports and reflections at least cast some doubts about the two general assumptions that underlie handbook statements like those cited above: (1) everyone benefits from intensive oral preparation; (2) the more often you rehearse your presentation, the better (i.e. more charismatic) you will be in the end. The present paper also has no empirical evidence to confirm or qualify the myth of intensive preparation. However, what we can do here is to pick up on two important restrictions that are left out in connection with this myth in many rhetoric manuals.

First, intensive oral rehearsal is only effective if the speaker rehearses in front of an audience. Niebuhr and Tegtmeier (2019) conducted a series of experiments in which they let their entrepreneurship students rehearse investor pitches in different conditions, i.e. alone in a quiet room (which is in fact the prototypical rehearsal condition), in front of a real audience (of peers and friends), and in front of an audience of virtual speakers in a virtual-reality presentation training environment. They found that the prototypical rehearsal condition, i.e. presenting alone in a quiet room to no audience or only an imaginary one, fails to make speakers significantly better (according to listener ratings in a perception experiment). It requires an audience to make one's presentation performance more charismatic after repeated rehearsal and, noteworthy from a practical perspective, it makes no significant difference whether this audience is real or virtual.

Second, Niebuhr and Tegtmeier showed that too intensive rehearsal causes what they call a "speech erosion effect", i.e. a significant reduction in the charismatic performance of the presentation, which is then also carried over by speakers into the actual presentation event. The speech-erosion effect already sets in if the pitch is practiced aloud more than three times in a row. However, rehearsing in front of a real or virtual audience can attenuate the speech-erosion effect. Only a few rhetoric manuals like the Speaker's Handbook of Sprague et al. (2013) caution their readers against this speech-erosion effect. Sprague et al. (2013: 326) state that "some speakers rehearse their pitch so much that is becomes mechanical", and they consider this "over-preparation" a "common pitfall".

Bottom line: Is the myth that a charismatic performance requires intensive training correct? The answer to this question is yes and no. Until proven otherwise, it is reason- 
able to assume that intensive rehearsal of a presentation is beneficial for the charismatic impact of a speaker in the actual speech. The data from Niebuhr and Tegtmeier (2019) provide first empirical evidence for the positive effect of rehearsal. However, rehearsing per se is not always positive. It can even make a speaker significantly less charismatic. Presentation rehearsal is beneficial only when it takes place in front of an audience and when the presentation is practiced no more than three times in direct succession. We recommend that speakers take a half day break between their rehearsal dyads or triplets.

\section{Myth 10: Engineers are less charismatic}

Anthony Fasano (2013) starts his rhetorical work Wow the Crowd: Anthony Fasano's Guide to Public Speaking for Engineers with the following anecdote: "Even though I have been a professional speaker for three years as of the publication of this guide, I still introduce myself as an engineer. People often joke and say, 'You can't be an engineer, engineers don't speak well in front of an audience.' This is one of the reasons that I wanted to prepare this comprehensive guide on public speaking for engineers".

That engineers are less charismatic than other speakers of the same sex and age but with a different profession and academic background is probably more a cliché than a real myth (in the sense of the introductory definition) and, in particular, not a topic that is addressed in many rhetoric manuals. Nevertheless, we decided to include this point here in our 10 myths about speaker charisma because of its societal and economic relevance. Both authors have university affiliations to technology and engineering departments. Moreover, the second author gives mandatory university courses in Persuasive Communication and Negotiation to business and electrical engineering students and regularly works with engineers in start-up incubators across different countries. Against this background, it is the authors' joint experience that engineers typically base their career on the mindset that good ideas, constructions, and technologies sell themselves. They would not require a persuasive person who sells them, just someone who is able to transform all facts and figures into intelligible spoken language and/or a text-loaded Power Point presentation.

We have included the present section in this paper for two reasons; first, to emphasize that good ideas, constructions, and technologies do not simply sell themselves. They do require someone who is able to push these good ideas/constructions/technologies through to investors, supervisors, and even the team who is eventually in charge of implementing them. Soorjoo (2012) explains this fact very clearly in chapter 1 of his book on how to pitch, get funded, and win clients. The second reason is that we have initial empirical evidence that engineers are indeed less charismatic than otherwise similar speakers with a different profession and academic background. As part of the second author's charisma training, a performance score is calculated for each speaker, based on a recorded (unscripted) presentation in front of a real audience (of typically 10-30 listeners); see Niebuhr et al. (2019). This performance score decomposes the speaker's speech signal into 16 acoustic parameters, assesses, for each parameter separately, how well the speaker performs and then provides a single total performance value to which each parameter contributes according to its power in triggering perceived speaker charisma. Currently, there are 466 such performance scores in the speaker database. Figure 5 shows the pat- 


\section{Charisma levels of rhetorically untrained speakers broken down by profession $(n=466)$}

Managers Bankers Engineers $\square$ Teachers

78

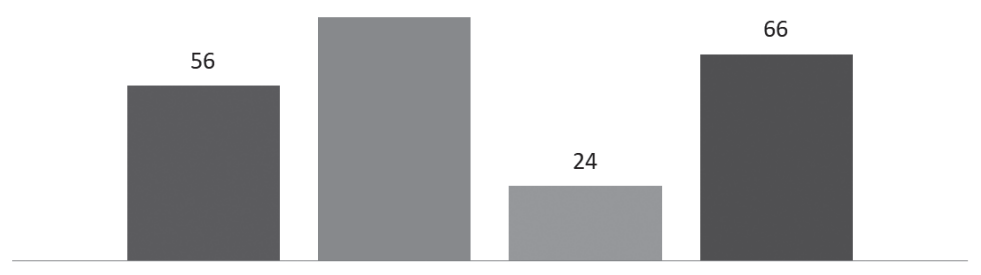

Mean Charisma Score (0-100)

Figure 5. Rounded mean charisma scores/levels of rhetorically untrained speakers broken down by the 466 speakers' professional backgrounds, i.e. managers, bankers, engineers, and teachers.

tern that emerges, if this database is broken down by professions. The engineers' mean charisma score is significantly lower (on average 64\% lower) than that of speakers with other professions (23.6). Speakers with a banking/economic background score highest (78.4), followed by teachers (66.1) and speakers with a management background (55.8).

Bottom line: Yes, engineers are less charismatic, at least in terms of initial empirical evidence from a sample of 466 advanced Western Germanic student or early-career speakers whose presentation delivery was analyzed with respect to their tone-of-voice performance. Obviously, this excludes body language, the design of presentation slides, and how the message itself is put into words; cf. the Charismatic Leadership Tactics of Antonakis et al. $(2011,2016)$. However, firstly, the speaker's tone-of-voice is a major factor for perceived speaker charisma and, secondly, there is no counterevidence (either anecdotal or empirical) that engineers perform better along these excluded factors than in their tone of voice. Further research is needed at these points. The poor performance of engineers in charismatic speech is potentially a loss in terms of a society's innovation and leadership (and hence economic and wealth) potential. It seems worth tackling that problem, for example, by including mandatory charisma courses into engineering education programs or by increasing the inherent motivation to take part in such courses. Such a motivation booster could be the recent finding of a significant correlation between charisma scores and course grades of engineering students (Niebuhr and Michalsky 2019b).

\section{Discussion}

In this paper we have addressed ten of the most common and often repeated myths about charisma and the way charisma manifests itself in speech. For each of the 10 myths, we have investigated its potential origin, reviewed the corresponding recommendations from the advice literature, i.e. primarily rhetoric manuals, and explained whether or not it is supported by empirical evidence. The 10 myths we investigated contribute to the demystification of charisma and the establishment of a measurable research and training 
object. We have shown that the existing charisma myths are not categorically false. Several fundamental assumptions in the advice literature such as "everyone can improve his/ her charismatic performance" or "charismatic performances require intensive training" are supported by modern cross-disciplinary research. However, there are many misconceptions when it comes to the phenomenological details. The advice to lower the voice supports charisma-related concepts like dominance and authority, but not charisma itself. The assumptions to increase a charismatic tone of voice through an upright posture, belly breathing and fewer/no filled pauses are all directly contradicted by empirical research. An upright posture could still be useful when it comes to a speaker's visual charisma, but it does not enhance the acoustic charisma triggers.

The upright posture is a good example of the state-of-the-art in understanding perceived speaker charisma. Two decades after the first empirical studies, we only have fragmentary knowledge about what speaker charisma actually is. There are three main reasons for this. First, the definition of charisma is still too vague. It is not just necessary to define the constituting features of charisma, as Antonakis et al. (2016) did, but also to separate charisma from related concepts. That is, we also need to state clearly at some point what charisma is not and why. Even empirical research still confuses charisma with concepts like attractiveness, dominance, assertiveness, power, likability, charm, leadership, and eloquence, all the more so in interdisciplinary studies. Semantic correlation analyses like those of Rosenberg and Hirschberg (2009) and Weninger et al. (2012) will help delimit the research object 'charisma' more thoroughly and they must be continued in the future.

Secondly, perceived speaker charisma is a complex, multifaceted phenomenon that requires an interdisciplinary approach. So far, scientific studies have barely acted on this cross-disciplinary potential. For example, concluding from the presented phonetic findings that speakers can sit while giving a speech and still be as charismatic as with a standing posture would be premature without taking into account the visual cues to charisma that, however, belong to a different research discipline. Additionally, factors like attire (Brem \& Niebuhr, 2019), size and age (Niebuhr et al., 2018b), culture (Ning, 2019), and the technical properties of signal transmission (cf. Gallardo \& Weiß, 2017) also play a role in charisma perception. Thus, besides linguistics and phonetics, charisma involves social sciences, political sciences, business sciences, psychology (social, personality and organizational), as well as ethnology, biology, aesthetics, media science, physics, and, last but not least, pedagogy. A broad and in-depth understanding of speaker charisma can only emerge from close collaborations between these research disciplines, preferably already at the stage of study design.

Thirdly, in order to analyze a complex multi-modal phenomenon such as speaker charisma, special measurement methods are needed; in particular those methods that allow for precise monitoring of acoustic, articulatory or cognitive processes and that are at the same time non-intrusive, adaptive and, preferably, mobile. Digital technologies ranging from virtual reality through smart phone apps and mobile EEGs to posture and gesture analyses with MS Kinect (Chen et al., 2014) have only emerged in recent years and will contribute greatly to advance charisma research in the future. The use of Respiratory Inductance Plethysmography (RIP, Włodarczak \& Heldner, 2016) to investigate and debunk Myth 8 is exemplary for how technological innovations can advance charisma 
understanding. The authors of this paper developed two instrumental-phonetic procedures relevant to charisma research (see Figure 6). PASCAL (Prosodic Analysis of Charismatic Speech: Assessment and Learning) breaks down a speaker's acoustic voice and melody profile into 16 charisma relevant parameters, allows to track and visualize these parameters in real time, and gives (sex-specific) feedback based on an algorithm that has been trained on perception data from hundreds of listeners from Western Germanic languages (cf. Niebuhr et al., 2019). MARRYS (Mandible Action-Related RhYthm Signals) is a special headgear for the measurement of speech rhythm. It builds on findings of Erickson and Kawahara (2016) that mandible movements (i.e. the dynamics and degrees of mouth opening) in speech are a robust correlate of perceived syllable prominence. On this basis, MARRYS will be used for future research on Myth 6 .
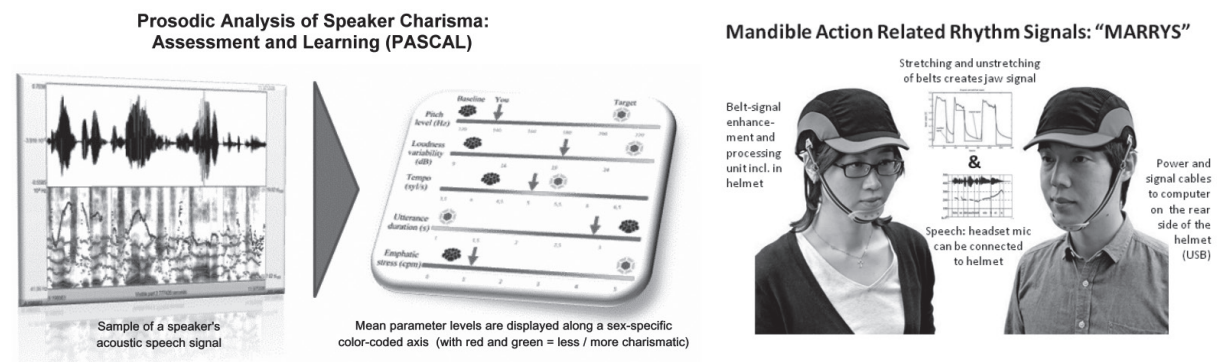

Figure 6. Illustration of two instrumental-phonetic methods PASCAL (left) and MARRYS (right) developed by the authors and their co-workers for the measurement, analysis, and assessment of charisma features.

Another technology-driven way of investigating charisma and its impact on listeners is using robots and talking machines. Works of Fischer (2018) or Niebuhr and Michalsky (2019) show that listeners interpret the acoustic charisma cues in synthetic voices in the same way as for human speakers. But, unlike for human speakers, the acoustic output of talking machines can be precisely controlled and exactly replicated. Furthermore, external factors influencing charisma such as sex, size, skin color, attire, or attractiveness are less likely to bias listener ratings of perceived charisma (if at all) if the "speaker" is a robot or a talking machine. Current experiments investigate the cross-cultural differences in the perception of charismatic voices by means of talking robots.

When it comes to practical challenges and questions for future research, revisiting the 10 myths yielded valuable insights. Although we know that a raised rather than lowered $f_{0}$ level is required in charismatic speech, Niebuhr and Skarnitzl (2019) showed that we still do not fully understand what the acoustic correlate of perceived $f_{0}$ level is. A study by Niebuhr et al. (2018a) showed additionally that also local $f_{0}$ events such as pitch accents and their $f_{0}$ shape contribute to the perceived $f_{0}$ level. The interaction between $f_{0}$, perceived pitch, and factors like speaking rate and vowel transitions is also not fully resolved (Michalsky, 2016; Barnes et al., 2012). Another unsettled issue is that of clear pronunciation. We showed that articulatory precision is important. However, when it comes to the links between articulatory precision, articulatory effort, and speaking rate, the parametric interplay in charisma perception is anything but well researched. We have also only 
scratched the surface with respect to pauses, breathing, hesitations and filled pauses. For example, what about dental clicks (i.e., sucking one's teeth) as pause fillers and the prosody of filled pauses? Initial evidence suggests that dental clicks are a real "charisma killer" in that they are interpreted by listeners as a signal of self-punishment or dissatisfaction of the speaker with his/her own current performance. Another big question concerns Myth 4 and the actual relation between charismatic effects of delivery and content. Finding answers to this question also means looking in more detail at how charisma is neurologically or cognitively processed. These sciences have barely been involved in charisma research so far (see Schjoedt et al., 2011 for one of the few exceptions).

Over and above the provided research overview, the present paper touched upon several practical questions in charisma or, more generally, leadership training. We know that charisma can be learned and makes a difference, but we have little knowledge about how and why charisma works from a cognitive point of view. We do not know for how long a charismatic influence persists, whether charisma has only a short-term or a long-term effect, and even less is known about cross-cultural charisma effects. In addition, charisma probably also varies across individuals. As is described in Myth 3, little is known about how a speaker's personality affects the learnability and expression of charisma, and barely anything is known about how a listener's personality affects the charisma perception of a speaker. The same set of questions can be asked for speaker and listener sex, although a lot of research has already gone into them. In speaker training, the lack of research in all these areas bears the risk of overgeneralizing charisma instructions across individuals, languages and cultures.

We are also just beginning to grasp how charisma is best trained and learned. Antonakis et al. (2011) identified, in the form of their CLTs, key elements for a charismatic impression. Phonetic research elaborated on the CLT element named "animated voice" by identifying the specific acoustic features of a charismatic tone of voice. However, there is still much to be done. Linguistic research is inconclusive about the persuasive effect of many CLTs such as metaphors (Sopory \& Dillard, 2002) and rhetorical questions (Ahluwalia \& Burnkrankt, 2004), and phonetic research still has to address questions of speaker sex, culture, language, personality and many more.

Moreover, further research has to be done on the order in which charisma techniques should be trained. Learning lexical CLT strategies before addressing the speaker's "animated voice" seems to yield overall stronger improvements than in the opposite order, since some rhetorical CLTs can prime certain prosodic strategies. Additionally, male speakers should focus more on lexical and female speakers more on tone-of-voice improvements (Niebuhr \& Wrzeszcz, 2019). Research on Myth 4 has also implications on how to weight the training of non-verbal and verbal strategies. How long do we have to train charisma in general to achieve the best effect in as short a time as possible, and how much training leads to sustainable improvements? Are there other training areas that indirectly foster charisma, such as the training of creativity, imagination or expressivity? Lastly, charisma is still regarded as a skill restricted to leadership and useful only to top managers, business leaders and politicians. However, what about teachers, advisors, consultants, actors or physicians? Beyond Myth 10, which professions are actually at a disadvantage when it comes to a lack of charisma? 
Finally, technological advances not only provide advantages for research on speaker charisma. They can also take the assessment and learning of charisma to a new level. Measurement techniques like RIP, PASCAL, and MARRYS, and the use of speech synthesis as a learning tool all hold a big potential for training charisma, as they allow to assess charisma and identify specific weaknesses and strengths on detailed objective grounds on which personalized, effective trainings can be built. That is, measurement and visualization techniques can give feedback on a phenomenon that is otherwise largely subjective and difficult to grasp and train. They make the soft skill charisma far less soft and, thus, pave the way for a new era of leadership and public-speaking training that is shaped by science and digitization.

\section{ACKNOWLEDGMENTS}

We are greatly indebted to Radek Skarnitzl and our two anonymous reviewers for their insightful and constructive comments on an earlier draft of this manuscript. They helped us a lot to make the paper understandable and relevant across disciplines. Furthermore, thanks are due to Heike Schoormann and Pauline Welby for their careful proofreading of the revised manuscript. We would also like to thank Jana Neitsch, Stephanie Berger, Jørgen Jakob Friis, Cordula Vesper, Jana Voße, and, in fact, all participants in our charisma-training seminars for many inspiring, exciting, and sometimes challenging discussions. Additional thanks go to Lars Penke, Thomas Schultze-Gerlach, and Julia Stern as well as to the whole department of personality psychology and organizational psychology at the University of Göttingen for insightful discussions about Myth 4 and to Alexander Brem, the Chair of Technology Management of the FAU Nuremberg-Erlangen for his committed aid in investigating phonetic charisma. Finally, we would like to express our special gratitude to Dante and Ernst for their patience and continuous support and encouragement. This work was partly funded by the Danish Council for Independent Research under Grant No. 7059-00101A.

\section{REFERENCES}

Ahluwalia, R. \& Burnkrankt, R. E. (2004). Answering Questions about Questions: A Persuasion Knowledge Perspective for Understanding the Effects of Rhetorical Questions. Journal of Consumer Research, $31,26-42$.

Amon, I. (2016). Die Macht der Stimme. Munich: Redline.

Antonakis, J., Bastardoz, N. \& Jacquart, P. (2016). Charisma: an ill-defined and ill-measured gift. Ann. Rev. Organ. Psychol. Organ. Behav., 3, 293-319.

Antonakis, J., Fenley, M. \& Liechti, S. (2011). Can charisma be taught? Tests of two interventions. Acad. Manag. Learn. Educ., 10, 374-396.

Antonakis, J., d'Adda, G., Weber, R. \& Zehnder, C. (2015). “Just words? Just speeches?” On the economic value of charismatic leadership. In: Working Paper. Department of Organizational Behavior, University of Lausanne.

Awamleh, R. \& Gardner, W. L. (1999). Perceptions of leader charisma and effectiveness: The effects of vision content, delivery, and organizational performance. The Leadership Quarterly, 10, 345-373. 
Barbosa, P. A. \& Niebuhr, O. (submitted). Persuasive speech is a matter of acoustics and chest breathing only. Journal of Speech Sciences.

Barker, A. (2011). Improve Your Communication Skills. London: Replika Press.

Barnes, J., Veilleux, N., Brugos, A. \& Shattuck-Hufnagel, S. (2012). Tonal Center of Gravity: A global approach to tonal implementation in a level-based intonational phonology. Laboratory Phonology, 3, 337-383.

Barrick, M. R. \& Mount, M. K. (1991). The Big Five personality dimensions and job performance: A meta-analysis. Personnel Psychology, 44, 1-26.

Bass, B. M. (1985). Leadership and Performance Beyond Expectations. New York: Free Press.

Batrinca, L., Stratou, G., Shapiro, A., Morency, L.-P. \& Scherer, S. (2013). Cicero - towards a multimodal virtual audience platform for public speaking training. In: Proceedings Intelligent Virtual Agents 2013, 116-128, Edinburgh, UK.

Bell, R. L. (2011). Is your speech filled with um? 3 tips to eliminate filled pauses from your professional presentation. Retrieved from https://www.researchgate.net/publication/261551832_Is_your _speech_filled_with_um_3_tips_to_eliminate_filled_pauses_from_your_professional_presentation (last access: 13 June, 2019).

Berger, S., Niebuhr, O. \& Peters, B. (2017). Winning over an audience - a perception-based analysis of prosodic features of charismatic speech. in: Proceedings 43rd Annual Meeting of the German Acoustical Society, 793-796.

Biadsy, F., Rosenberg, A., Carlson, R., Hirschberg, J. \& Strangert, E. (2008). A cross-cultural comparison of American, Palestinian, and Swedish perception of charismatic speech. In: Proc. Speech Prosody 2008, 579-582. Campinas, Brazil.

Brem, A. \& Niebuhr, O. (2019). Dress to Impress? On the Interaction of Attire with Prosody and Gender in the Perception of Speaker Charisma. In: M. Barkat-Defradas, B. Weiss, J. Trouvain \& J. J. Ohala (Eds.), Voice Attractiveness: Studies on Sexy, Likable, and Charismatic Speakers. New York: Springer Nature.

Camper Bull, R. (2010). Moving from Project Management to Project Leadership: A practical guide to leading groups. Boca Raton: CRC.

Cangemi, F., Clayards, M., Niebuhr, O., Schuppler, B. \& Zellers, M. (Eds.) (2018). Rethinking Reduction: Interdisciplinary Perspectives on Conditions, Mechanisms, and Domains for Phonetic Variation. Berlin: Walter de Gruyter.

Carnegie, D. \& Esenwein, J. B. (2011). The Art of Public Speaking. London: Walking Lion.

Caspi, A., Bogler, R. \& Tzuman, O. (2019). “Judging a Book by Its Cover”: The Dominance of Delivery Over Content When Perceiving Charisma. Group \& Organization Management. DOI: https://doi. org/10.1177/1059601119835982.

Chen, A., Gussenhoven, C. \& Rietveld, T. (2002). Language-specific uses of the Effort Code. In: Proc. Speech Prosody 2002, 211-214.

Chen, L., Feng, G., Joe, J., Leong, C. W., Kitchen, C. \& Lee, C. M. (2014). Towards automated assessment of public speaking skills using multimodal cues. In: Proceedings 16th International Conference on Multimodal Interaction (Istanbul).

Clingingsmith, D. \& Shane, S. (2017). Training aspiring entrepreneurs to pitch experienced investors: Evidence from a field experiment in the United States. Management Science, 64(11), 5164-5179.

Clopper, C. G., Turnbull, R., Cangemi, F., Clayards, M., Niebuhr, O., Schuppler, B., \& Zellers, M. (2018). Exploring variation in phonetic reduction: Linguistic, social, and cognitive factors. In: Cangemi, F. et al. (Eds.), Rethinking Reduction: Interdisciplinary Perspectives on Conditions, Mechanisms, and Domains for Phonetic Variation (pp. 25-72). Berlin: Walter de Gruyter.

Corley, M. \& Hartsuiker, R. J. (2003). Hesitation in speech can ...um... help a listener understand. In: Proc. 25th Annual Meeting of the Cognitive Science Society.

Costa, P. T. \& McCrae, R. R. (1992). NEO PI-R Professional Manual. Odessa, FL: Psychological Assessment Resources.

Curhan, J. R. \& Brown, A. D. (2012). Parallel and divergent predictors of objective and subjective value in negotiation. In: K. S. Cameron \& G. M. Spreitzer (Eds.), Oxford Handbook of Positive Organizational Scholarship (pp. 579-590). New York, NY: Oxford University Press. 
D'Errico, F., Niebuhr, O. \& Poggi, I. (2019). Humble voices in political communication: A speech analysis across two cultures. Lecture Notes in Computer Science 11620, 361-374.

Daniels, N. (2013). How to train your voice to become more charismatic. Retrieved from https://like3net.blogspot.com/2015/09/how-to-train-your-voice-to-be-more_14.html (last access 13 June, 2019).

Davies, J. C. (1954). Charisma in the 1952 campaign. Am. Polit. Sci. Rev., 48, 1083-1102.

D’Errico, F., Signorello, R., Demolin, D. \& Poggi, I. (2013). The perception of charisma from voice. A crosscultural study. Proc. Humaine Association Conference on Affective Computing and Intelligent Interaction, pp. 552-557. Geneva, Switzerland.

Emrich, C. G., Brower, H. H., Feldman, J. M. \& Garland, H. (2001). Images in words: Presidential rhetoric, charisma, and greatness. Administrative Science Quarterly, 46, 527-557.

Erickson, D. \& Kawahara, S. (2016). Articulatory correlates of metrical structure: Studying jaw displacement patterns. Linguistics Vanguard, 2(1): https://doi.org/10.1515/lingvan-2015-0025.

Etzioni, A. (1964). Modern Organizations. Englewood Cliffs, NJ: Prentice Hall.

Fasano, A. (2013). Wow the Crowd: Anthony Fasano's Guide to Public Speaking for Engineers. Retrieved from https://engineeringmanagementinstitute.org/wow-crowd-engineers-guide-public-speaking/ (last access: 13 June, 2019).

Fischer, K. (2000). From Cognitive Semantics to Lexical Pragmatics: The Functional Polysemy of Discourse Markers. Mouton de Gruyter.

Fischer, K. (2018). Talking to robots. In: Elmentaler, M. \& Niebuhr, O. (Eds.), An den Rändern der Sprache. Notes of a lecture series at Kiel University. Retrieved from https://www.uni-kiel.de/ pressemeldungen/index.php?pmid=2018-084-rv-sprache\&pr=1. (last access 13 June, 2019).

Fox Cabane, O. (2012). The Charisma Myth: How Anyone Can Master the Art and Science of Personal Magnetism. New York: Penguin.

Fox Tree, J. E. (2001). Listeners' uses of um and uh in speech comprehension. Memory and Cognition, 29, 320-326.

Frese, M., Beimel, S. \& Schoenborn, S. (2003). Action training for charismatic leadership: Two evaluations of studies of a commercial training module on inspirational communication of a vision. Personnel Psychology, 56, 671-697.

Fruehwald, J. (2016). Filled Pauses as a Sociolinguistic Variable. U. Penn Working Papers in Linguistics, $22,41-49$.

Gallardo, L. F. \& Weiß, B. (2017). Towards Speaker Characterization: Identifying and Predicting Dimensions of Person Attribution. In: Proc. Interspeech 2017, 904-908.

Gemmill, G. \& Oakley, J. (1992). Leadership: an alienating social myth? Hum. Relations, 45, 113-129.

Goman, K.G. (2008). The nonverbal advantage - Secrets and science of body language at work. San Francisco: Berrett-Koehler.

Gregory, S. W. Jr. \& Gallagher, T. J. (2002). Spectral analysis of candidates' nonverbal vocal communication: predicting U.S. presidential election outcomes. Soc. Psychol. Q., 65, 298-308.

Gussenhoven, C. (2016). Foundations of intonational meaning: Anatomical and physiological factors. Topics in Cognitive Science, 8(2), 425-434.

Hargrave, J. (1995). Let me see your body talk. Dubuque: Kendall/Hunt.

Holladay, S. J. \& Coombs, W. T. (1993). Communicating visions: An exploration of the role of delivery in the creation of leader charisma. Management Communication Quarterly, 6, 405-427.

Holladay, S. J. \& Coombs, W. T. (1994). Speaking of visions and visions being spoken an exploration of the effects of content and delivery on perceptions of leader charisma. Management Communication Quarterly, 8, 165-189.

House, R. J. (1977). A 1976 theory of charismatic leadership. In: J. G. Hunt \& L. L. Larson (Eds.), The Cutting Edge (pp. 189-207). Carbondale, IL: S. Ill. Univ. Press.

Howell, J. M. \& Frost, P. J. (1989). A laboratory study of charismatic leadership. Organizational Behavior and Human Decision Processes, 43(2), 243-269.

John, O. P. \& Srivastava, S. (1999). The Big-Five trait taxonomy: History, measurement, and theoretical perspectives. In: L. A. Pervin \& O. P. John (Eds.), Handbook of Personality: Theory and Research, Vol. 2, (pp. 102-138). New York, NY: Guilford Press.

Judge, T. A. \& Piccolo, R. F. (2004). Transformational and Transactional Leadership: A Meta-Analytic Test of Their Relative Validity. Journal of Applied Psychology, 89(5), 755-768. 
Kraus, N. (2015). Deutlich sprechen lernen in 7 Tagen. Nico Kraus Verlag.

Levinson, S. (1983). Pragmatics. Cambridge: Cambridge University Press.

Mayew, W. J., Parsons, C. A. \& Venkatachalam, M. (2013). Voice pitch and the labor market success of male chief executive officers. Evolution and Human Behavior, 34(4), 243-248.

McAleer, P., Todorov, A. \& Belin, P. (2014). How Do You Say 'Hello’? Personality Impressions from Brief Novel Voices. PLoS ONE, 9(3): e90779.

Michalsky, J. (2016). Perception of pitch scaling in rising intonation. On the relevance of $f_{0}$ median and speaking rate in German. In: Proceedings of $P \nLeftarrow P$ 12, Munich, Germany.

Michalsky, J., Kordsmeyer, T., Niebuhr, O. \& Penke, L. (2019). Prosodic correlates of dominance and self-assurance. Acoustic cues to testosterone related personality states of male speakers. In: Proc. 1st International Seminar on the Foundations of Speech.

Mixdorff, H., Niebuhr, O. \& Hönemann, A. (2018). Model-based prosodic analysis of charismatic speech. In: Proc. Speech Prosody 2018.

Mortensen, K. W. (2011). The Laws of Charisma: How to Captivate, Inspire, and Influence for Maximum Success. New York: Amacom.

Niebuhr, O., Voße, J. \& Brem, A. (2016). What makes a charismatic speaker? A computer-based acoustic prosodic analysis of Steve Jobs tone of voice. Computers and Human Behavior, 64, 366-382.

Niebuhr, O., Tegtmeier, S. \& Brem A. (2017). Advancing research and practice in entrepreneurship through speech analysis - from descriptive rhetorical terms to phonetically informed acoustic charisma metrics. Journal of Speech Sciences, 6, 3-26.

Niebuhr, O. (2017). Clear Speech - Mere Speech? How segmental and prosodic speech reduction shape the impression that speakers create on listeners. In: Proc. Interspeech 2017, 894-898.

Niebuhr, O., Thumm, J. \& Michalsky, J. (2018a). Shapes and timing in charismatic speech - Evidence from sounds and melodies. In: Proc. Speech Prosody 2018, 582-586.

Niebuhr, O., Skarnitzl, R., and Tylečková, L. (2018b). The acoustic fingerprint of a charismatic voice Initial evidence from correlations between long-term spectral features and listener ratings. In: Proc. Speech Prosody 2018, 359-363.

Niebuhr, O. \& Gonzalez, S. (2019). Do sound segments contribute to sounding charismatic? Evidence from acoustic vowel space analyses of Steve Jobs and Mark Zuckerberg. International Journal of Acoustics and Vibration, 24, 343-355.

Niebuhr, O. \& Michalsky, J. (2019). Computer-generated speaker charisma and its effects on human actions in a car-navigation system experimen - Or how Steve Jobs' tone of voice can take you anywhere. Lecture Notes in Computer Science 11620, 375-390.

Niebuhr, O. \& Fischer, K. (2019). Do not hesitate! - Unless you do it shortly or nasally: How the phonetics of filled pauses determine their subjective frequency and perceived speaker performance. In: Proc. Interspeech 2019.

Niebuhr, O. \& Tegtmeier, S. (2019). Virtual-reality as a digital learning tool in entrepreneurship - How virtual environments help entrepreneurs give more charismatic investor pitches. In: R. Baierl, J. Behrens \& A. Brem (Eds.), Digital Entrepreneurship: Interfaces Between Digital Technologies and Entrepreneurship. Berlin: Springer Nature.

Niebuhr, O. \& Wrzeszcz, S. (2019). A woman's gotta do what a woman's gotta do, and a man's gotta say what a man's gotta say - Sex-specific differences in the production and perception of persuasive power. In: Proc. 13th International Pragmatics Association Conference.

Niebuhr, O. \& Skarnitzl, R. (2019). Measuring a speaker's acoustic correlates of pitch - but which? A contrastive analysis based on perceived speaker charisma. In: Proceedings of 19th International Congress of Phonetic Sciences.

Niebuhr, O., Tegtmeier, S. \& Schweisfurth, T. (2019). Female speakers benefit more than male speakers from prosodic charisma training - A before-after analysis of 12-weeks and 4-h courses. Frontiers in Communication, $4,12$.

Ning, L. (2019). What makes a speaker sound charismatic? A cross-cultural study based on acoustic-prosodic analysis. MA thesis, Chair of Technology Management, University of Erlangen-Nuremberg, Germany.

Novák-Tót, E., Niebuhr, O. \& Chen, A. (2017). A gender bias in the acoustic melodic features of charismatic speech? In: Proc. Interspeech 2017. 
Pangambam, S. (2016). Let's Face It: Charisma Matters by John Antonakis. Retrieved from https:// singjupost.com/lets-face-it-charisma-matters-by-john-antonakis-full-transcript/ (last access: 13 June, 2019).

Park, S., Shoemark, P. \& Morency, L.-P. (2014). Toward crowd-sourcing micro-level behavior annotations: The challenges of interface, training, and generalization. In: Proceedings of the 18th International Conference on Intelligent User Interfaces.

Pentland, A. (2008). Honest Signals - How They Shape Our World. Cambridge: MIT Press.

Peters, J. (2015). Charisma: How to Develop Personal Charisma and Leave that Lasting Impression on Everyone You Meet. CreateSpace Independent Publishing Platform.

Polla, B., D’Antona, G., Bottinelli, R. \& Reggiani, C. (2004). Respiratory muscle fibres: Specialisation and plasticity. Thorax, 59(9), 808-817.

Rosenberg, A. \& Hirschberg, J. (2009). Charisma perception from text and speech. Speech Communication, 51, 640-655.

Salomoni, S., van den Hoorn, W. \& Hodges, P. (2016). Breathing and singing: Objective characterization of breathing patterns in classical singers. PLoS ONE, 11, e0155084.

Schegloff, E. A. (2010). Some other "Uh(m)"s. Discourse Processes, 47, 130-174.

Scherer, S., Layher, G., Kane, J., Neumann, H. \& Campbell, N. (2012). An audiovisual political speech analysis incorporating eye-tracking and perception data. In: Proc. LREC'12.

Schjødt, H., Stodkilde-Jorgensen, A. W., Geertz, T. E. \& Lund, A. (2010). The power of charisma-perceived charisma inhibits the frontal executive network of believers in intercessory prayer social cognitive and affective. Neuroscience, 6, 119-127.

Seet, J. (2013). Speak Clearly: Crisp Clear Pronunciation. Retrieved from http://sgskill.com/?page=course _calendar\&id=1097\&m=9\&y=2013 (last access: 13 June, 2019).

Shamir, B. \& Howell, J. M. (1999). Organizational and contextual influences on the emergence and effectiveness of charismatic leadership. Leadership Quarterly, 10, 257-283.

Shamir, B., Arthur, M. B. \& House, R. J. (1994). The rhetoric of charismatic leadership: A theoretical extension, a case study, and implications for research. The Leadership Quarterly, 5, 25-42.

Sharma, S., Bottom, W. \& Elfenbein, H. A. (2013). On the role of personality, cognitive ability, and emotional intelligence in predicting negotiation outcomes: A meta-analysis. Organizational Psychology Review, 3(4), 293-336.

Smith, R. R. (2010). Overcoming charisma. Forbes Magazine. Retrieved from https://www.forbes .com/2010/02/25/charisma-presence-communication-leadership-managing-speaking.htm 1\#4c4770716730 (last access 13 June, 2019).

Soorjoo, M. (2012). Here's the Pitch: How to Pitch Your Business to Anyone, Get Funded, and Win Clients. Hoboken: John Wiley \& Sons.

Sopory, P. \& Dillard, J. P. (2002). The persuasive effects of metaphor. A meta-analysis. Human Communication Research, 28, 382-419.

Speech and Voice (2019). How breathing can improve your voice. Retrieved from https://www.speechand voice.com/speech-voice-improvement-tips/how-breathing-can-improve-voice/ (last access: 13 June, 2019).

Sprague, J., Stuart, D. \& Bodary, D. (2013). The Speaker's Handbook. Boston: Wadsworth.

Strangert, E. \& Gustafson, J. (2008). What makes a good speaker? Subject ratings, acoustic measurements and perceptual evaluations. In: Proc. Interspeech 2008, 1688-1691.

Thorpe, C., Cala, S., Chapman, J. \& Davis, P. (2001). Patterns of breath support in projection of the singing voice. Journal of Voice, 15, 86-104.

Touati, P. (1993). Prosodic aspects of political rhetoric. In: Proc. ESCA Workshop on Prosody, 168-171.

Towler A. J. (2003). Effects of charismatic influence training on attitudes, behavior, and performance. Personnel Psychology, 56, 363-381.

Towler, A., Arman, G., Quesnell, T. \& Hoffman, L. (2014). How charismatic trainers inspire others to learn through positive affectivity. Computers in Human Behavior, 32, 221-228.

Tucker, R. C. (1968). The theory of charismatic leadership. Daedalus, 97, 731-756.

Volkmann, S. (2013). Der kleine Stimmkompass. Lebendig sprechen - punktgenau landen. 21 Impulse für Haltung, Stimme, Körpersprache. Silke Volkmann Verlag.

Weber, M. (1947). The Theory of Social and Economic Organization. New York: The Free Press of Glencoe. 
Weber, M. (1968). On Charisma and Institutional Building. Chicago: Univ. Chicago Press.

Weninger, F., Krajewski, J., Batliner, A. \& Schuller, B. (2012). The voice of leadership: Models and performances of automatic analysis in on-line speeches. IEEE Transactions on Affective Computing, 3, 496-508.

Włodarczak, M. \& Heldner, M. (2016). Respiratory belts and whistles: A preliminary study of breathing acoustics for turn-taking. In: Proc. Interspeech 2016, 510-514.

\section{RESUMÉ}

Charisma je složitým jevem, což se projevuje v množství mýtů, polopravd a nezodpovězených výzkumných otázek. Většina mýtů spojených s charismatem není bez kontroverze. Protože empirická zkoumání $\mathrm{v}$ posledních několika letech výrazně pokročila, vracejí se autoři tohoto příspěvku k deseti nejdůležitějším mýtům, které se týkají převážně, ale nikoli výhradně lingvistických a fonetických aspektů charismatu. K těm patří např́klad interakce mezi verbálními a neverbálními jevy a mezi segmentálními a prozodickými informacemi, ale také role dýchání a základní hlasové frekvence ve vnímání charismatičnosti mluvčího. Výsledkem je značně rozmanitý obrázek. Některé z představených mýtů, včetně některých velmi starých, mohou být přijaty. Jiné je třeba ve světle odporujících empirických výsledků odmítnout. Postavení některých dalších mýtů zůstává nezodpovězeno. Při diskusích o tomto rozmanitém obrázku autoři poukazují na mezery ve výzkumu a řečové praxi a navrhují konkrétní směry, jimiž by se další výzkum měl ubírat.

\section{Jan Michalsky}

Chair of Technology Management

Friedrich-Alexander-Universität Erlangen-Nürnberg, Germany

E-mail: jan.michalsky@uni-oldenburg.de

Oliver Niebuhr

Centre for Industrial Electronics

University of Southern Denmark, Sonderborg, Denmark

E-mail:olni@sdu.dk 